Bol. Acad. peru. leng. 68. 2020 (207-222)

\title{
Castellano andino de la provincia de Huamanga: distritos de Quinua y Pacaycasa
}

\section{Andean Spanish in the province of Huamanga: districts of Quinua and Pacaycasa}

\author{
Julissa Milagros Ruiz Villa \\ Universidad Nacional Mayor de San Marcos \\ julissaruiz.10.94@gmail.com \\ https://orcid.org/0000-0002-7701-6356
}

\section{Resumen:}

En el presente artículo, se aborda el análisis morfológico y sintáctico de la variedad del castellano andino, específicamente, de los distritos de Quinua y Pacaycasa que se ubican en la provincia de Huamanga, Ayacucho. Esta investigación es de corte metodológico descriptivoexplicativo, ya que se ha anotado una serie de ejemplos correspondientes a los diversos procesos gramaticales obtenidos. Asimismo, se ha incluido una breve descripción que contrasta con otros autores que versan mencionados temas.

Palabras clave: castellano andino, loísmo, diminutivo, discordancia de número, estructura oracional. 


\section{Abstract:}

In this paper, the morphological and syntactic analysis of the Andean Spanish variety, specifically, from the districts of Quinua and Pacaycasa, which are located in the province of Huamanga, Ayacucho. In this way, this research is methodologically descriptive and explanatory, since a series of examples corresponding to the diverse grammatical processes obtained have been noted. Furthermore, a brief description will be included which contrasts with other authors who deal with the aforementioned topics.

Key words: Andean Spanish, loísmo, diminutive, number discordance, sentence structure.

Fecha de recepción: $\quad$ 20/02/2020

Fecha de aceptación: $\quad$ 14/09/2020

\section{Introducción}

El español o castellano andino peruano es una variedad hablada en la región andina de nuestro país, producto de la confluencia con otras lenguas como el quechua y aimara, en el caso de Perú, Bolivia y Chile. Esta variedad tiene características en el componente fonológico, morfológico, sintáctico y léxico semántico, que presentan una clara influencia de la lengua andina.

En esta investigación, se analiza procesos gramaticales enmarcados en tres aspectos: en el morfológico, el diminutivo; en el sintáctico, el cambio de la estructura oracional y la discordancia de género; en el morfosintáctico, el loísmo; procesos gramaticales presentes, específicamente, en el dialecto del castellano hablado en los distritos de Quinua y Pacaycasa, provincia Huamanga, región Ayacucho, Perú. Asimismo, se tiene como objetivo describir la comparación y diferencia de los dialectos hablados en Quinua y Pacaycasa, así también de los hablantes del centro de Huamanga. 


\section{Antecedentes}

Algunos antecedentes sobre el castellano andino son los siguientes:

Gladys Merma Molina (2004), en su texto titulado «Lenguas en contacto: Peculiaridades del español andino peruano», analiza casos específicos frecuentes en el español andino en el campo de la morfosintaxis: el lo aspectual, la doble marcación de la posesión, el verbo dice con función oracional de validador referencial, entre otros.

Ana María Escobar (2000), en su libro titulado Contacto social y Lingüístico. El español en contacto con el quechua en el Perú, describe características morfológicas, sintácticas y semánticas presentes en el castellano andino, producto del contacto del quechua con el castellano. Uno de los aspectos característicos del castellano andino, en cuanto al componente morfológico, es la redundancia de diminutivos — generalmente, el alomorfo -ecito- al referirse al receptor con amabilidad. Por otro lado, Escobar, en su artículo «Dialectos del español de América: español andino», también resalta el uso del diminutivo como una característica peculiar del español andino. El diminutivo, señala, se da con frecuencia en sustantivos, adjetivos, adverbios y pronombres; también se registra en gerundios, aunque señala que la última forma no ha sido hallada, probablemente, porque este uso se vincula con los niños que poseen el español como segunda lengua.

Donald STARK (1970), en su investigación titulada Aspectos gramaticales del español hablado por los niños de Ayacucho, ofrece una serie de entrevistas realizadas a los niños de Ayacucho, donde, además, les pide que relaten anécdotas y actividades cotidianas. Entre una de sus conclusiones, supone que las diferencias gramaticales presentadas en el castellano andino pueden ser atribuidas al subestrato quechua y que las características específicas pueden ser explicadas por la variación dialectal.

\section{Alcances morfosintácticos}

El castellano andino se caracteriza por ser aglutinante, por la ausencia de artículo, la carencia de concordancia de género y número, la existencia de 
un solo sistema de conjugación enteramente regular, y la precedencia del modificador respecto de su núcleo: es decir, el adjetivo precede al nombre, el elemento posesor al elemento poseído, el objeto al verbo, la oración relativa a la FN-cabeza, y la subordinada a la principal (Cerrón-Palomino, 2003, p. 82). Además, esta variedad de castellano presenta una estructura sintáctica de orden SOV (Sujeto-Objeto-Verbo).

\section{Metodología}

Para la recolección de los datos, se siguió un patrón de preguntas abiertas de acuerdo al contexto. Por ejemplo, se entrevistó a dos comerciantes mientras desempeñaban la venta de comida, para lo cual se inició una conversación abierta con la finalidad de obtener datos que se aproximaran a un diálogo natural y fluido.

Sobre el trabajo de campo, se realizó una visita a la provincia de Huamanga, distritos de Quinua y Pacaycasa, en el año 2017; en el lugar, se entrevistaron a cinco hablantes, cuyas edades oscilaban entre los 13 y 64 años.

En cuanto a la organización del análisis, se extrajo entradas como una muestra de la existencia de los fenómenos gramaticales que presentan. Luego, se estructuró una regla de acuerdo con el proceso morfológico o sintáctico evidenciados. Es decir, se enlistaron las formas halladas y las formas esperadas para después extrapolar una regla general. Cabe señalar que se dividió el análisis en dos grupos: el español hablado en Quinua y el español hablado en el centro de Huamanga.

\section{Análisis}

\subsection{El español hablado en Quinua}

\subsubsection{Morfosintaxis}

\subsubsection{Loísmo}

A continuación, se muestran las evidencias encontradas relativas al fenómeno del loísmo. 


\section{Entrevista 2}

Entrada 23: 'A ese carro me lo subo'

Entrada 115: 'Tú lo ves una cosa'

Entrada 109: 'lo pisan a los gatitos'

Tabla 1

Comparación entre enunciados con loísmo y sin loísmo

\begin{tabular}{|c|c|}
\hline Forma hallada & Forma esperada \\
\hline Tú lo ves una cosa & Tú ves una cosa \\
\hline A ese carro me lo subo & A ese carro me subo \\
\hline Lo pisan a los gatitos & Pisan a los gatitos \\
\hline
\end{tabular}

En español, se espera la siguiente estructura:

$\mathrm{N}+$ Vtransitivo $+\mathrm{OD}$

$\mathrm{N}+$ Pronombre proclítico + Vtransitivo

Sin embargo, las estructuras sintácticas halladas en el español andino son las siguientes (respectivamente):

$\mathrm{N}+$ Pronombre proclítico + Vtransitivo $+\mathrm{OD}$

$\mathrm{OI}+\mathrm{N}$ tácito + Pronombres proclíticos $($ me y $l 0)+$ Vintransitivo

$\mathrm{N}$ tácito + Pronombre proclítico + Vtransitivo $+\mathrm{OD}$

En las entradas encontradas, se observa el uso innecesario de lo como pronombre proclítico, pues se supone que reemplaza al OD; sin embargo, se reitera el OD en la oración. Además, se utiliza con verbo transitivo en dos de las tres evidencias.

Gladys Merma Molina, en «Lenguas en contacto: Peculiaridades del español andino peruana» y en «Tres casos de interferencia morfosintáctica», señala que la inserción de lo sucede, generalmente, en verbos intransitivos, 
en comparación a lo encontrado en las entrevistas, donde la presencia de lo es usual en verbos transitivos. Sin embargo, esto no impide que también suceda en oraciones con verbos intransitivos, como se demuestra en la entrada 23.

En la entrada $A$ ese carro me lo subo, observamos que ese carro funciona como OI. En este caso, solo sería necesario el uso del pronombre me, pero el hablante inserta el pronombre $l o$, que es utilizado para reemplazar al OD.

En la forma hallada del castellano andino, se puede observar que los colaboradores nombran el objeto dos veces, probablemente, para enfatizarlo.

\subsubsection{Morfología}

\subsubsection{Diminutivo}

A continuación, se indica cada una de las evidencias encontradas para el caso morfológico relativo al uso extensivo del diminutivo.

\section{Entrevista 2}

Entrada 2: 'había un carrito'

Entrada 13: 'acacito en el nicho' 'acá abajito hay un nicho'

Entrada 15: 'cuando un almita ha muerto'

Entrada 25: 'más arribita también me ha pasado eso'

Entrada 42: 'es pesadito'

\section{Entrevista 4}

Entrada 18: '¿En esa parte de la chozita?'

Entrada 20: 'es su techadito no más'

\section{Entrevista 5}

Entrada 1: 'hay carteritas, chompas, chalinas,...'

Entrada 2: 'ahí ta' torito, a quince soles'

Entrada 10: 'ahí ta', esa parejita'

Entrada 18: 'bonitos son esos sombreritos' 


\author{
Entrada 21: '¿estito?' \\ Entrada 37: 'gorritos de cuero también' \\ Entrada 38: 'ollita de abundacia' \\ Entrada 48: 'Estito pe', así marroncito, bonito ¿sí o no?' \\ Entrada 60: 'tiene crucifiquito también'
}

\title{
5.1.2.1.1. Diminutivos en sustantivos y adjetivos
}

Se aceptan los morfemas derivativos como -it, -cit o ecit. Si terminan en vocal átona «a» $\mathrm{u}$ «0», tienden a utilizar el sufijo -it, con lo cual las palabras bisilábicas se convierten en trisilábicas. En aquellas palabras cuya última sílaba es -za o -zo, no obstante, la «z» será presentada como «c», puesto que se emplea dicha letra ante las vocales «e» e «i», lo cual deriva en la forma -cit.

Tabla 2

Diminutivo en sustantivos y adjetivos

\begin{tabular}{|l|l|}
\hline \multicolumn{2}{|c|}{ Sustantivos } \\
\hline Carro + it $+o=$ carrito & Alma $+\mathrm{it}+\mathrm{a}=$ almita \\
\hline Choza + cit $+\mathrm{a}=$ chocita & Cartera $+\mathrm{it}+\mathrm{a}=$ carterita \\
\hline Toro $+\mathrm{it}+\mathrm{o}=$ torito & Toro $+\mathrm{it}+\mathrm{o}=$ torito \\
\hline Pareja $+\mathrm{it}+\mathrm{a}=$ parejita & Sombrero $+\mathrm{it}+\mathrm{o}=$ sombrerito \\
\hline Crucifijo $+\mathrm{it}+\mathrm{o}=$ crucifiquito & Gorro $+\mathrm{it}+\mathrm{o}+\mathrm{s}=$ gorritos \\
\hline Olla $+\mathrm{it}+\mathrm{a}+\mathrm{s}=$ ollitas & Regalo $+\mathrm{it}+\mathrm{o}=$ regalito \\
\hline \multicolumn{2}{|c|}{ Adjetivos } \\
\hline Marrón + cit $+\mathrm{o}=$ marroncito & Pesado $+\mathrm{it}+\mathrm{o}=$ pesadito \\
\hline
\end{tabular}

\subsection{Diminutivos en adverbios}

El sufijo -it, con sus alomorfo -cit, puede adherirse a bases adverbiales. 
Tabla 3

\section{Diminutivo en adverbios}

\begin{tabular}{|c|}
\hline Adverbios \\
\hline Acá + cit $+\mathrm{o}=$ acacito \\
\hline Abajo + it $+\mathrm{o}=$ abajito \\
\hline Arriba + it $+\mathrm{a}=$ arribita \\
\hline
\end{tabular}

Como se observa, hay una presencia excesiva de diminutivos en sustantivos, adjetivos y adverbios, con una mayor frecuencia de uso en los primeros. En el caso de los adjetivos y adverbios, no se evidenció tanta ocurrencia de este fenómeno, por lo menos en Quinua.

Anna María Escobar (2000) señala que el quechua emplea distintos recursos lingüísticos en el uso del diminutivo para expresar cortesía (-lla), acercamiento simbólico a la persona del interlocutor y su afectividad $(-y k u)$, intensificación de la relación afectiva (-rqo), exhortación incoativa y referencia a una acción ya iniciada (-ri) (-sha). Así, debido a las evidencias encontradas, las características que más resaltan son la cortesía y la relación de afectividad del interlocutor, las cuales están presentes en el castellano andino mediante la utilización de sufijos. Por ello, concluimos que existe influencia del quechua en el castellano andino en cuanto a la referencia de un contexto determinado.

Asimismo, podemos señalar que la intención del hablante cuando utiliza diminutivos en los adverbios de tiempo y lugar es enfatizar la proximidad del lugar o del suceso que ocurre. Por otro lado, el uso de los diminutivos en los adverbios de modo, de acuerdo al contexto en el que se presentan, su uso podría deberse a la intención de enfatizar la exactitud de la acción.

Vlastimil Rataj, en su tesis La influencia del quechua en el español andino (2005), indica que, a diferencia de lo que se espera en el español estándar, el español andino presenta los diminutivos en categorías 
léxicas inusuales, por ejemplo, adverbios, pronombres, numerales, etc. Sobre la base de nuestras evidencias, coincidimos con lo señalado por este autor, especialmente, en el caso del único pronombre en diminutivo del que tenemos evidencia, y del que, apoyados por este texto, podemos decir que es parte de una de las peculiares características del español andino.

\subsubsection{Sintaxis}

\subsubsection{Cambio de la estructura oracional}

Se presenta la variación de la estructura oracional SVO a SOV.

\section{Entrevista 2}

Entrada 70: '(mi papá) ganadero es'

Entrada 93: 'Quinua lugar turístico es'

Entrada 13: 'Esa ruta de atrás peligroso es'

\section{Entrevista 4}

Entrada 45: 'Por la comida solo (pagas).'

La regla planteada para el caso de cambio estructural oracional SOV es la siguiente:

Tabla 4

Estructura oracional del castellano, el quechua y el castellano andino

\begin{tabular}{|c|c|c|}
\hline \multicolumn{3}{|c|}{ Estructura oracional } \\
\hline En castellano & En quechua & En castellano andino \\
\hline SVO & SOV & SOV \\
\hline
\end{tabular}

Para el análisis de este fenómeno sintáctico, se tiene en consideración la teoría de principios y parámetros de la gramática generativa. A continuación, a través de los siguientes esquemas, se constata el cambio en la estructura oracional del castellano en la variedad castellano andino. 
Julissa Milagros Ruiz Villa

https://doi.org/10.46744/bapl.202002.008

Figura 1

Esquema arbóreo de la estructura oracional esperada en castellano

SFlex

SN

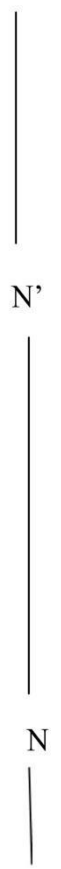

Quinua
Flex'

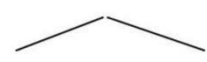

Flex

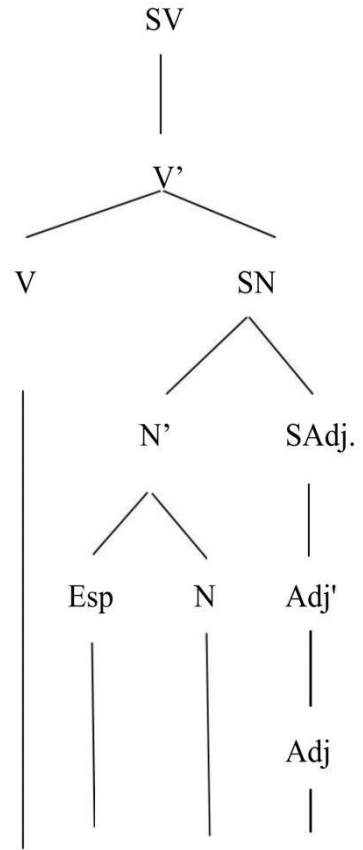

es un lugar turístico 


\section{Figura 2}

Esquema arbóreo de la estructura oracional hallada en castellano andino

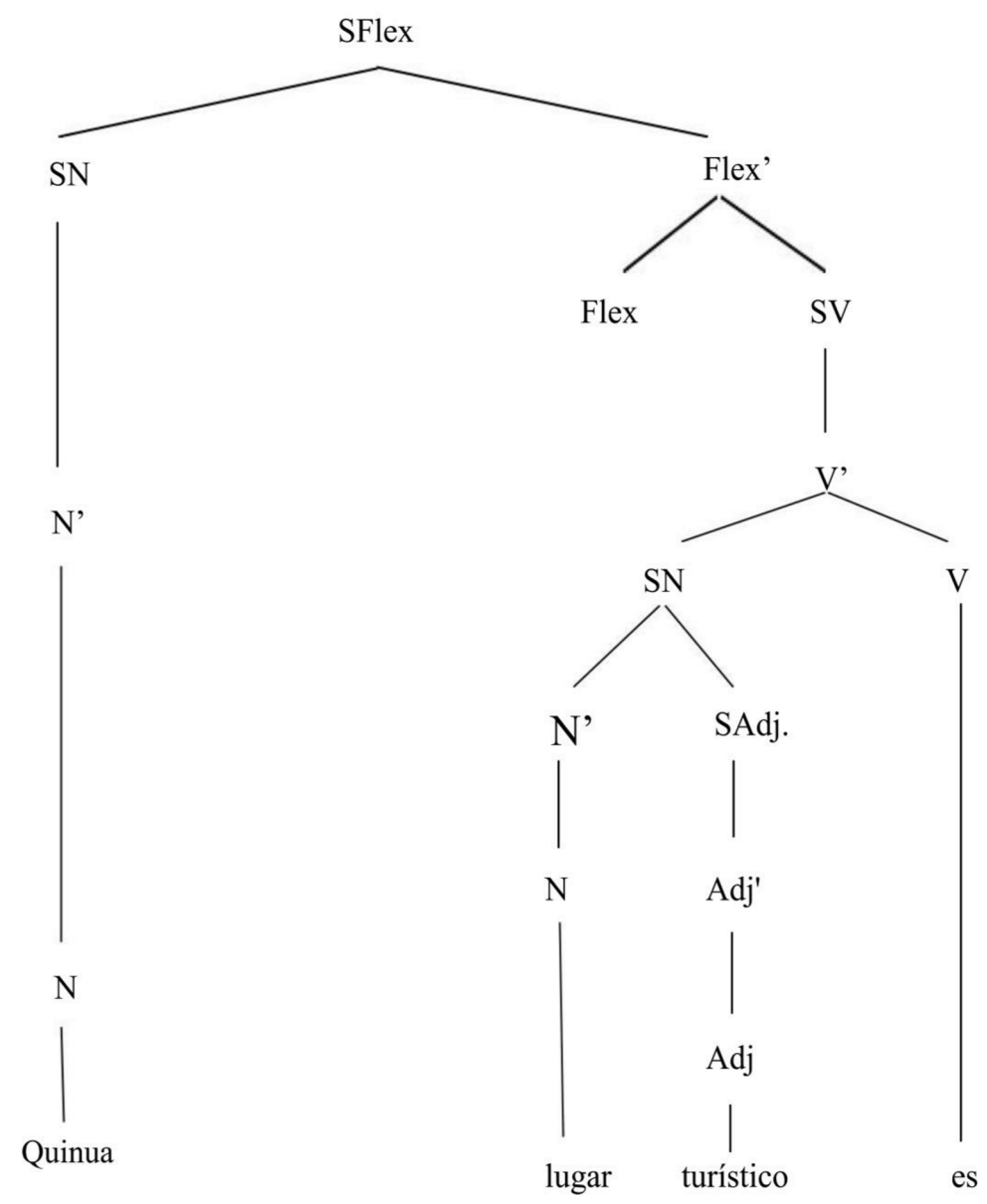

En la forma hallada, no solo se observa el intercambio de posición entre verbo y atributo, sino también la omisión del determinante. 
Respecto de las evidencias mostradas, se observa el cambio de la estructura sintáctica en las oraciones simples en contraste con la forma esperada SVO y la forma SOV. Asimismo, la mayoría de las oraciones están formadas con verbo copulativo, por lo que, probablemente, en el castellano regional andino hablado en Quinua es más usual que ocurra este cambio oracional con verbos no transitivos.

La forma SOV hallada se explica a través de la influencia del quechua. Por un lado, Cerrón Palomino (2003) evidencia que esta estructura cambia cuando se trata de oraciones subordinadas; sin embargo, en este caso, son oraciones simples. Además, se sabe que las características tipológicas del quechua son cambiantes, por ejemplo, Cerrón Palomino registra en su análisis las estructuras sintácticas tanto SVO, SOV, OVS.

Por otra parte, Donald Stark (1970) supone que las diferencias gramaticales presentadas en el castellano andino pueden ser atribuidas al substrato quechua. Además, estas características específicas pueden ser explicadas por la variación dialectal.

A partir de lo señalado por los autores Donald y Cerrón, se concluye que el contacto de lenguas entre el castellano y el quechua contribuye a la influencia de aspectos particulares de una lengua a otra. Para este caso en particular, el orden general del castellano se ha visto influenciado por la estructura sintáctica particular del quechua.

\subsection{El español de centro de Huamanga}

\subsubsection{Sintaxis}

\subsubsection{Discordancia de número}

\section{Entrevista 3}

Entrada 44: 'Un provinciano siempre somos'

'Cinco soles era verdes'

Entrada 62: 'El pueblo ya están viendo eso' 
Castellano andino de la provincia de Huamanga: distritos de Quinua y Pacaycasa https://doi.org/10.46744/bapl.202002.008

Existen dos tipos de discordancia de número:

Tabla 5

Comparación entre enunciados con discordancia de número y sin discordancia de número

\begin{tabular}{|c|c|}
\hline \multicolumn{2}{|c|}{ Discordancia de número en determinantes } \\
\hline Forma hallada & Forma esperada \\
\hline El cereales & Los cereales \\
\hline Un provincianos siempre somos & Los provincianos siempre somos \\
\hline \multicolumn{2}{|c|}{ Discordancia de número en sujeto-verbo } \\
\hline Forma hallada & Forma esperada \\
\hline Era verdes & Eran verdes \\
\hline El pueblo ya están viendo eso & El pueblo ya está viendo eso \\
\hline Son eucalipto & Es eucalipto \\
\hline Habían un curso & Había un curso \\
\hline
\end{tabular}

En español, se espera la siguiente estructura sintáctica:

Det (sing.) + Nombre (sing.) / Det (pl.) + Nombre (pl.)

Nombre (sing.) + Verbo (sing.) / Nombre (pl.) + Verbo (pl.)

Sin embargo, se encontraron las siguientes estructuras de concordancia de número en español andino:

Det (sing.) + Nombre (pl.) / Det (pl.) + Nombre (sing.)

Nombre (sing.) + Verbo (pl.) / Nombre (pl.) + Verbo (sing.)

Cerrón-Palomino (2013) señala que, en cuanto a la discordancia de número, la «desviación» se manifiesta en la inmovilización en favor del determinante. En otras palabras, para la concordancia entre el determinante y el nombre, el primero debería adecuarse a la concordancia del segundo; por lo tanto, las formas esperadas son las que hemos descrito en el cuadro 
de discordancias. En cuanto a la concordancia de sujeto-verbo, CerrónPalomino advierte que la categoría gramatical de número en quechua se rige por reglas gramaticales diferentes a las del castellano: por ejemplo, para la tercera persona en quechua, la concordancia de sujeto-verbo es enteramente opcional.

Finalmente, por todo lo expuesto, coincidimos con CerrónPalomino, además de que los dos tipos de discordancia que se presentaron en el análisis se deben al contacto del quechua con el español: lo que es más, se observa de modo regular la discordancia de sujeto-verbo en el castellano andino.

\section{Conclusiones}

En cuanto a Pacaycasa, se encontró evidencia en oraciones de la entrevista 1 como Con la papa pequeños pedacitos lo acompaña el arroz, en la cual lo debería reemplazar a con pequeños pedacitos de papa; sin embargo, es utilizado nuevamente. El mismo fenómeno se evidencia en Huamanga, pero solo se encontró con verbos transitivos y no con verbos intransitivos, como ocurrió en Quinua. Cabe resaltar que el uso de lo solo con verbos transitivos se opone a lo planteado por autores como Gladys Merma.

Se encontraron datos parecidos en la provincia de Huamanga y Pacaycasa, y se afirma que ocurre la misma regla planteada para Quinua. En el español andino hablado en Huamanga, se observa una sola evidencia de concurrencia del sufijo diminutivo y sufijo aumentativo: comeloncito. Si bien esta confluencia de sufijos resulta inusual en el español, no tiene relevancia en el español andino, ya que el aumentativo y diminutivo pueden tener distintos significados, no necesariamente opuestos. Así, el morfo -lon puede referirse a que come bastante, mientras que el diminutivo -cit, a otro aspecto de la persona como el tamaño o el valor afectivo. Por ello, se puede inferir que el hablante da mayor importancia a uno de los dos sufijos: en este caso, a través del aumentativo, se busca expresar que la persona suele comer mucho. En Huamanga, contrario a Quinua, se evidencia mayor uso de diminutivos en los adverbios, por ejemplo: ahorita, aquicito, llegan igualitos, da vuelta rapidito. 
En Huamanga, en la entrevista 3, el fenómeno se evidenció en oraciones con verbo copulativo, mayormente. De acuerdo a estos casos y el de Quinua, se infiere que el cambio de estructura oracional en el español andino regional suele ocurrir en oraciones intransitivas, mientras que no se encontró evidencia alguna de este fenómeno en Pacaycasa.

En Quinua, en la entrevista 1, se evidenció - pero tan solo una vez- el fenómeno de discordancia de número en determinantes (Se comía el cereales). Asimismo, en Pacaycasa, en la entrevista 4, también existe evidencia de discordancia de número, pero de otro tipo: sujeto-verbo ( $L a$ parte de abajo son eucalipto y Habian un curso de quechua). Por lo tanto, hay manera de demostrar la discordancia de número en el castellano andino hablado en el centro de Huamanga y en los distritos de Quinua y Pacaycasa. 


\section{BIBLIOGRAFÍA}

BABEL, A. (2010). Contact and contrast in Valley Spanish. Tesis para obtener el Grado de Doctor. Michigan: Universidad de Michigan.

CERRÓN-PALOMINO, R. (2003). Castellano Andino. Aspectos sociolingüísticos, pedagógicos y gramaticales. Lima: Fondo Editorial PUCP.

ESCOBAR, A. (1978). Variaciones sociolingüísticas del castellano en el Perú. Lima: Instituto de Estudios Peruanos. . (2000). Contacto social y Lingüístico. El español en contacto con el quechua en el Perú. Lima: Fondo editorial PUCP.

MERMA, G. (2004). Lenguas en contacto: Peculiaridades del español andino peruano. Tres casos de interferencia morfosintáctica. ELUA, 18, pp. 191-211. Universidad de Alicante, Recuperado de https://rua.ua.es/dspace/bitstream/10045/6137/1/ ELUA_18_10.pdf

STARK, D. (1970). Aspectos gramaticales del español hablado por los niños de Ayacucho. Lima: Universidad Nacional Mayor de San Marcos.

VAQUero, A. (2011). El español de América II. Morfosintaxis y Léxico. Madrid: LAVEL, S.A. 